\title{
Cellular Structure and Function of Rat Fat Cells in the Primary Culture
}

\author{
Sadayuki Funatsumaru \\ Department of Pathology, Saga Medical School, Nabeshima 5-1-1, Saga 849, Japan
}

Key words: fat cell/lipolysis/lipogenesis/culture/proliferation/differentiation

\begin{abstract}
$A B S T R A C T$. A primary culture of undigested fat tissue fragments was used to obtain fat cells in vitro. On day 2 of culture, immature fat cells, which are fibroblast-like fat cells containing fine lipid droplets, appeared, surrounding the fat tissue fragments, and began to proliferate extensively. Afterwards, these fibroblast-like fat cells grew to become multilocular fat cells containing larger intracytoplasmic lipid droplets, and differentiated further into unilocular fat cells containing a single large intracytoplasmic lipid droplet.

Treatment with dibutyryl-cAMP, which is a second messenger of the lipolytic factor, caused the cultured fat cells to retract, and the intracytoplasmic lipid droplets of those fat cells became finely granulated and decreased along with an increase of hormone-sensitive lipase activities. Conversely, administration of insulin caused the lipid droplets in the fat cells to increase and become larger along with an increase of $\alpha$-glycerophosphate dehydrogenase activities. These findings indicate the occurrence of lipolysis and lipogenesis of fat cells in vitro.

Immuno-cytochemistry revealed that vimentin surrounded intracytoplasmic lipid droplets, and became distinct with an increase of lipid droplets through lipogenesis in the fat cells. Vimentin seems to be correlated to the behavior of lipid droplets in the fat cells.

Fat cells in this study showed the appropriate cellular structures and functions in response to stimulation of lipolysis and lipogenesis under culture conditions. It is expected that in vitro culture of fat cells will facilitate cell biological elucidation of obesity in the future.
\end{abstract}

Mature white fat tissue, which consists of mature fat cells and immature fat cells, plays an important role in the storage of energy and lipid metabolism. Fat cells have many kinds of hormone receptors, and are metabolically active $(1,2,11,12,15,19,20,27,28,29)$. A cell biological study of fat cells would be most helpful in elucidating the mechanism of obesity. However, only a few studies on cellular behavior of fat cells in vitro have been reported, due to the difficulty of culturing fat cells.

Mature fat cells, called unilocular fat cells, have a large single intracytoplasmic lipid droplet, and have been considered to be technically difficult to culture because of their buoyancy in culture media $(12,28)$. For this reason, most of the studies on fat cells have been carried out using biochemical methods on dissociated fat cells obtained from collagenase-digested mature fat tissue (20) or monolayer culture of immature fat cells, called preadipocytes $(1,2,11,12,19,27,28,29)$, and established cell lines of preadipocytes $(9,15)$.

Recently, Sugihara, et al. $(23,24,26)$ described a new

Abbreviations: dibutyryl-cAMP, N6-2'-dibutyryl adenosine-3'-5'cyclic monophosphate Na salt; HSL, Hormone-sensitive lipase; $\alpha$ GPDH, $\alpha$-Glycerophosphate dehydrogenase; G6PDH, Glucose-6phosphate dehydrogenase; pan-ras oncogene products, $\mathrm{H}-, \mathrm{K}$ - and $\mathrm{N}$ ras oncogene products. method designated as "ceiling culture", by which unilocular fat cells can be cultured by making use of their buoyant tendency. By this method, dissociated unilocular fat cells adhered to the inner upper surface (ceiling surface) in a medium-filled flask. Afterwards, they changed into fibroblast-like fat cells and proliferated extensively until reaching confluency. As mentioned above, this was a culture method using digested fat cells. Sugihara et al. (25) then developed a similar method that was applicable to fat tissue, because it is most common in cell biological studies to use undigested tissue fragments. This can also be called a ceiling culture method because the tissue fragments float in the culture medium. Fibroblast-like fat cells derived from undigested mature fat tissue fragments appeared around the tissue fragments, where they proliferated extensively. After becoming confluent, they differentiated at a high rate into multilocular and unilocular fat cells. These phenomena, that is, the proliferation and differentiation of fat cells from mature fat tissue, appear to reflect the physiological cell behavior of fat tissue in vivo.

Here, I present a histochemical study of cellular morphology and function in lipolysis and lipogenesis, the two principle characteristics of fat cells, using a primary culture of fat tissue. 


\section{MATERIALS AND METHODS}

Materials. The material used for culture was abdominal subcutaneous fat tissue obtained from 6- to 7-day-old male Wistar rats.

Cell culture. The primary culture to obtain fat cells in vitro was based on the new method of "ceiling culture", which was reported elsewhere $(23,24,26)$. The present method, however, differs from the original method in that instead of using fat cells dissociated with collagenase, undigested fat tissue fragments were employed (25). It also differs from the original "ceiling culture" method because the adherence surface of the floating fat tissue fragments was not the inner surface of the flask, but the undersurface of a cover glass (this method was reported by Kumei et al.) (14). The cover glass method was used because it is more convenient in cytochemical procedures using cultured fat cells (Fig. 1).

Briefly, fat tissue from the rat was chopped into very small pieces $(0.2-0.3 \mathrm{~mm})$ and centrifuged at low speed $(700 \mathrm{rpm})$ in a buffer solution. The floating tissue fragments consisting of rich mature fat cells were obtained. These fragments were incubated in medium, and a cover glass was floated on the medium. This culture dish was incubated at $37^{\circ} \mathrm{C}$ and in $5 \% \mathrm{CO}_{2}$. On day 2 of culture, the incubated fat tissue fragments, which rose to the top of the medium, tightly adhered to the undersurface of the cover glass. At this time, the cover glass was inverted and sunk into the medium in order to revert to regular culture conditions. The culture medium consisted of HamF12 supplemented with $20 \%$ newborn calf serum and $50 \mu \mathrm{g}$
$/ \mathrm{ml}$ gentamicin.

Chemicals added to the cultured cells. The following chemicals were added to some cultures: 1) $1 \mathrm{mM} \mathrm{N}^{6}-2^{\prime}$-dibutyryl adenosine-3'-5'-cyclic monophosphate Na salt (dibutyrylcAMP (Seikagaku-kogyo, Japan), which is a second messenger for lypolytic factor and promotes lipolysis; and 2) $1 \mathrm{mU}$ /ml insulin (Sigma, St. Louis, MO), which promotes lipogenesis.

Examination of cultured cells. Fat cells growing in culture were examined by the following procedures: 1) phase-contrast microscopy. 2) lipid histochemistry using Oil-red O/hematoxylin stain. 3) enzyme histochemistry of hormone-sensitive lipase (HSL) (18), $\alpha$-glycerophosphate dehydrogenase ( $\alpha$-GPDH) (16) and glucose-6-phosphate dehydrogenase (G6PDH) (17). 4) for determination of glycerol in the medium, an enzymatic method (4) was adopted. Briefly, glycerol was reacted with glycerokinase, pyruvate kinase, and lactate dehydrogenase. The amount of NADH consumed in these reactions is stoichiometric with respect to glycerol. NADH was determined by its absorption at $340 \mathrm{~nm}$. 5) examination of proliferation; Labeling reagent (bromodeoxyuridine (BrdU) $2 \mu \mathrm{l}, 30 \mathrm{mg} / \mathrm{ml})(7,8)$ was added to $2 \mathrm{ml}$ of culture medium and cultured for 3 to 8 hours. Fat cells on the cover glass, fixed with $30 \%$ acetatic ethanol, were incubated with antiBrdU antibody by the procedures specified in the BrdU kit (Cell proliferation kit, Amersham, Arlington Heights, IL).

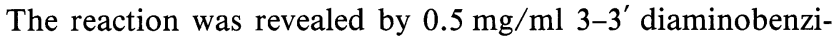
dine tetrahydrochloride (Sigma, St. Louis, MO) and $3 \mu \mathrm{l} / \mathrm{ml}$ $\mathrm{H}_{2} \mathrm{O}_{2}$ in $50 \mathrm{mM}$ Tris-buffered saline, $\mathrm{pH}$ 7.5. Five hundred

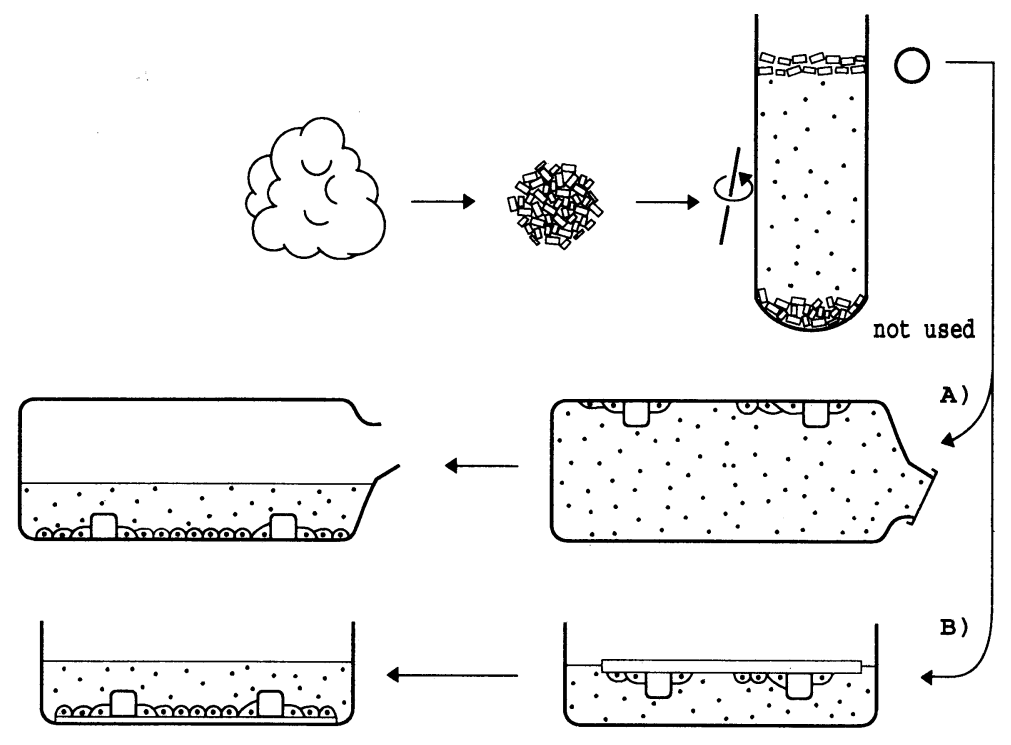

Fig. 1. Ceiling culture of mature fat tissue fragments in original method (A) and present method (B). Mature white fat tissue was chopped into small pieces and centrifuged. Sediments were not used in this culture. In method A, in which fat tissue fragments are incubated in a flask that was filled with medium, the fragments attached themselves to the inner upper surface of the flask (ceiling surface). In method B, in which floating tissue fragments covered with a cover glass were incubated in a culture dish, the fragments floated to the top of the medium and adhered to the undersurface of the cover glass. When the fragments had firmly attached themselves, the flasks were placed upside down to allow for regular observation. Fibroblast-like fat cells proliferated extensively from the tissue fragments. 
Fat Cells in Culture

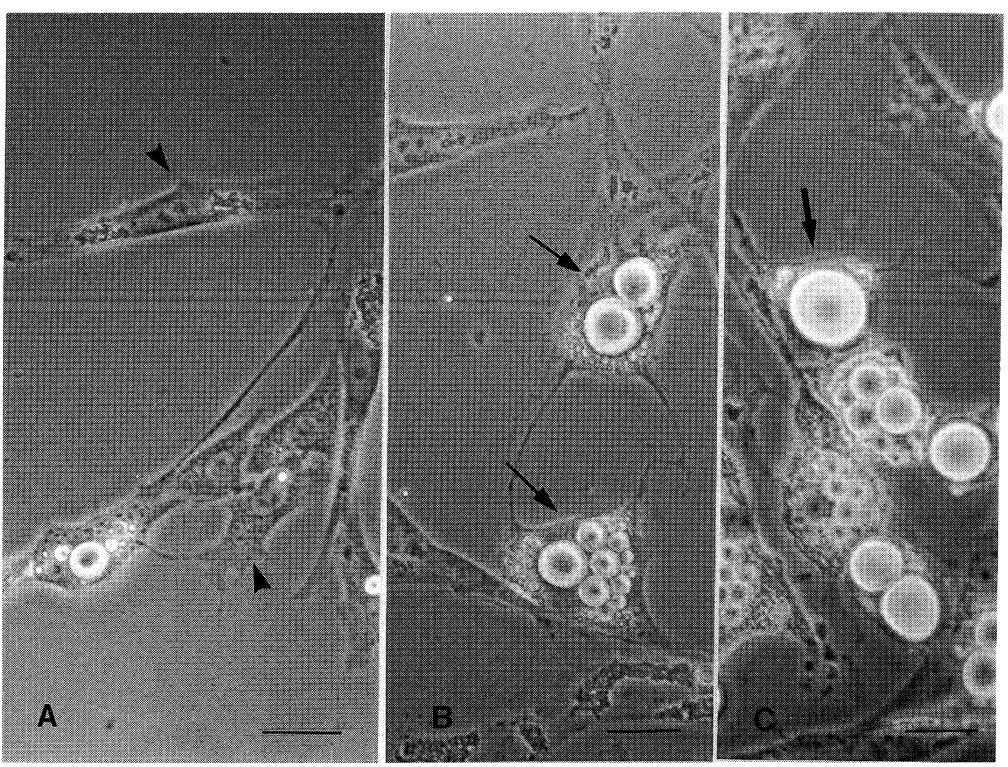

Fig. 2A-C. Phase-contrast micrograph of fat cells derived from mature fat tissue fragments on day 3 of culture. A, fibroblast-like fat cell containing fine intracytoplasmic lipid droplets (arrowhead); B, multilocular fat cells containing many larger lipid droplets (thin arrow); C, unilocular fat cells containing a single lipid droplet (thick arrow). Bar, $30 \mu \mathrm{m}$.

cells were counted to estimate the labeling index. 6) immunohistochemical examinations: 1. rearrangement of the vimentin cytoskeleton during adipose conversion using monoclonal anti-vimentin antibody (Labosystems OY, Helsinki) (5); 2. localization of S-100 protein, which is considered to be a carrier protein in the cytoplasm of fat cells, using monoclonal anti-S-100 protein antibody (Chemicon International, California) (10); 3. expression of c-neu oncogene product of cell proliferation using monoclonal anti-c-neu oncogene product antibody (Oncogene science, Inc., New York) (13); 4. expression of pan-ras (H-, K-, N- ras) oncogene products of cell proliferation using monoclonal anti-pan-ras oncogene products antibody (Oncogene Science, Inc., New York) (6). In these immuno-histochemistries, reaction products were revealed by the diaminobenzidine (DAB) method described above.

\section{RESULTS}

Cell culture. In a ceiling culture of fat tissue fragments, fragments became attached to the undersurface of a floating cover glass on day 2 of culture. Some fibroblast-like fat cells which had a few fine intracytoplasmic

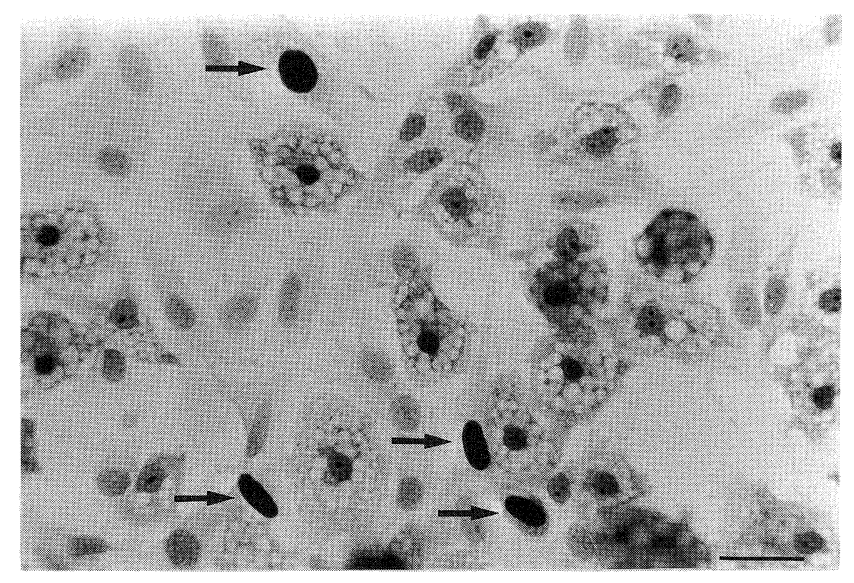

Fig. 3. Immunohistochemistry of bromodeoxyuridine (BrdU) by anti-BrdU antibody of cultured fat cells. Four nuclei (arrow) of fibroblastlike fat cells that have a few lipid droplets show positive results, while nuclei of multilocular fat cells are negative. Bar $30 \mu \mathrm{m}$. 
lipid droplets appeared around those fat tissue fragments, and began to proliferate extensively (Fig. 2A). On day 3 of culture, these fibroblast-like cells grew to multilocular fat cells containing enlarged intracytoplasmic lipid droplets (Fig. 2B). The intracytoplasmic lipid droplets increased in number, and grew larger, finally differentiating into unilocular fat cells containing a single large lipid droplet (Fig. 2C). These droplets were positive by Oil red $\mathrm{O}$ stain which was taken as an indication of differentiation of the fat cells. Upon further culturing, the fat cells grew to confluency.

The cultured fat cells were roughly divided into three groups according to their state of differentiation and proliferative potentiality: immature proliferative fibroblast-like fat cells, transitional typed-multilocular fat cells and mature differentiated unilocular fat cells. The proliferative potentiality of these cells was confirmed by uptake of BrdU. In the examination of BrdU uptake, the nuclei of fibroblast-like fat cells were positively immunostained with anti-BrdU antibody at a rate of 15 to $20 \%$ for 3 hours on day 3 of culture, and the rates of positive staining of multilocular fat cells and unilocular fat cells were both below 1\% (Fig. 3).

Cellular morphological and histochemical findings in lipolysis and lipogenesis of cultured fat cells.

A) Cell morphology. Four hour treatment with 1

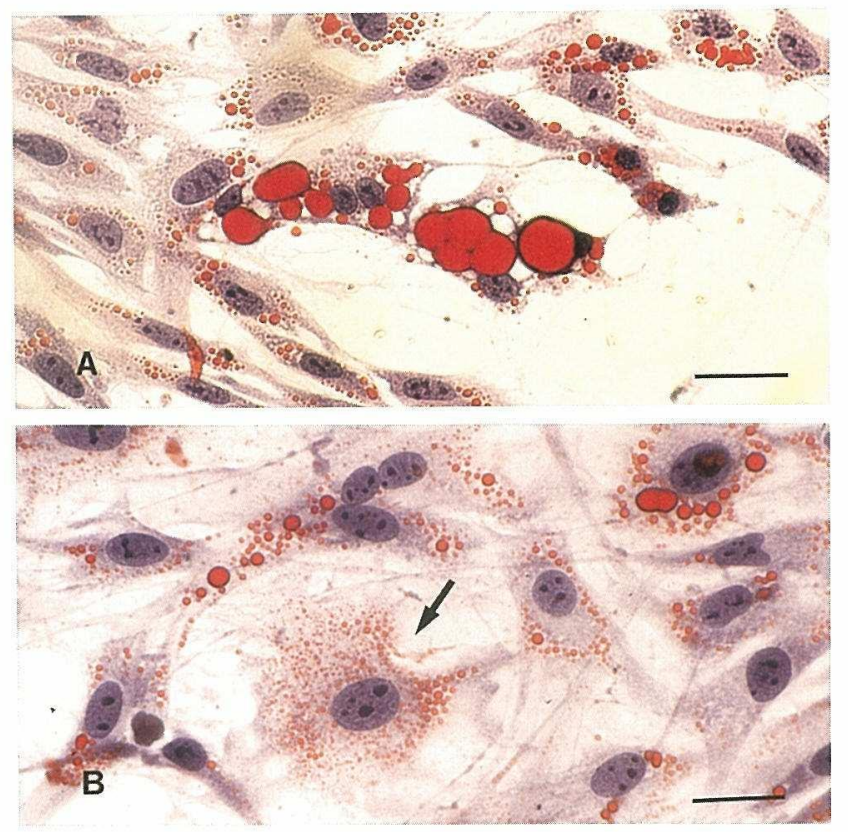

Fig. 4A \& B. Morphological changes of cultured fat cells caused by stimulation of lipolysis. A, control (no treatment); B, treatment for 4 hours with $1 \mathrm{mM}$ dibutyryl-cAMP on day 3 of culture. The intracytoplasmic lipid droplets of cultured fat cells became finely granulated (arrow) and the cells retracted. Oil red O/Hematoxylin stain. Bar, 30 $\mu \mathrm{m}$.
mM dibutyryl-cAMP caused lipolysis of the cells: the cultured fat cells retracted, and the intracytoplasmic lipid droplets became finely granular. At the same time, the glycerol content in the medium increased at a rate of $2 \mu \mathrm{mol} / 10^{5}$ cells per $60 \mathrm{~min}$. Strikingly, these changes occurred in both multilocular fat cells and fibroblastlike fat cells. In cultured fat cells, specifically, in the multilocular fat cells, finely granularized intracytoplasmic lipid droplets were observed arranged along the radial cytoplasmic processes (Fig. 4A, B).

On the other hand, addition of $1 \mathrm{mU} / \mathrm{ml}$ insulin to the medium for 7 days caused lipogenesis: the cultured fat cells enlarged and became rounder in conjunction with the increase in intracytoplasmic lipid droplets. In the fibroblast-like fat cells, the nuclei moved to the cen-
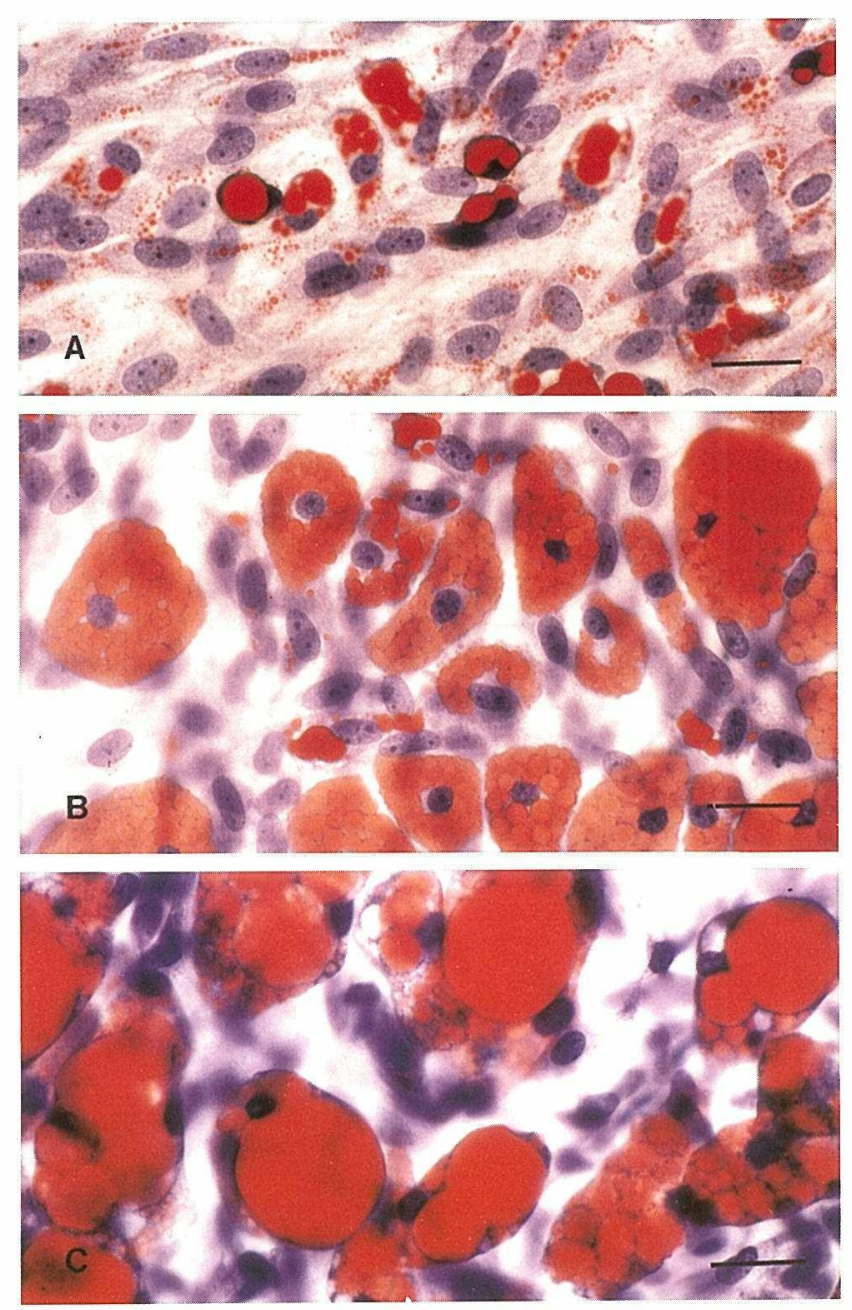

Fig. 5A-C. Morphological changes of cultured fat cells caused by stimulation of lipogenesis. A, control (no treatment); B \& C, administration for 7 days of $1 \mathrm{mU} / \mathrm{ml}$ insulin in culture. The intracytoplasmic lipid droplets of cultured fat cells increased, and multilocular (B) and unilocular (C) fat cells are observed. Bar, $30 \mu \mathrm{m}$. 

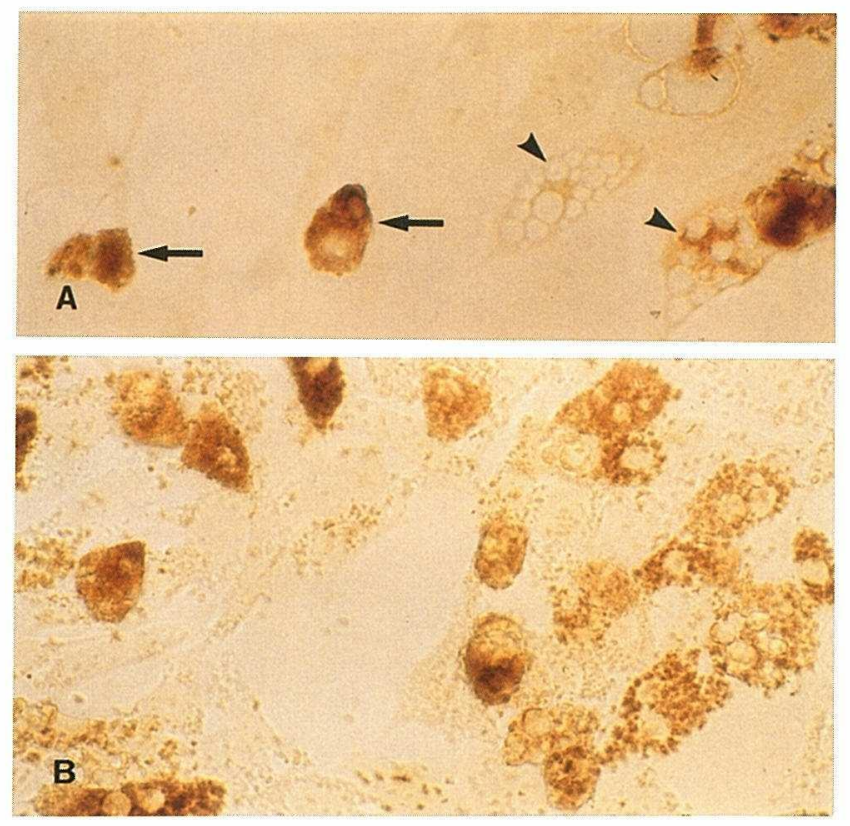

Fig. 6A \& B. Changes in HSL activity caused by stimulation of lipolysis in cultured fat cells. A, control (no treatment). HSL activity in cytoplasm appears strong in round fat cells (arrow), but is weak in multilocular fat cells (arrowhead); B, treatment for 4 hours with 1 $\mathrm{mM}$ dibutyryl-cAMP on day 3 of culture. HSL activity in cytoplasm of fat cells increased.
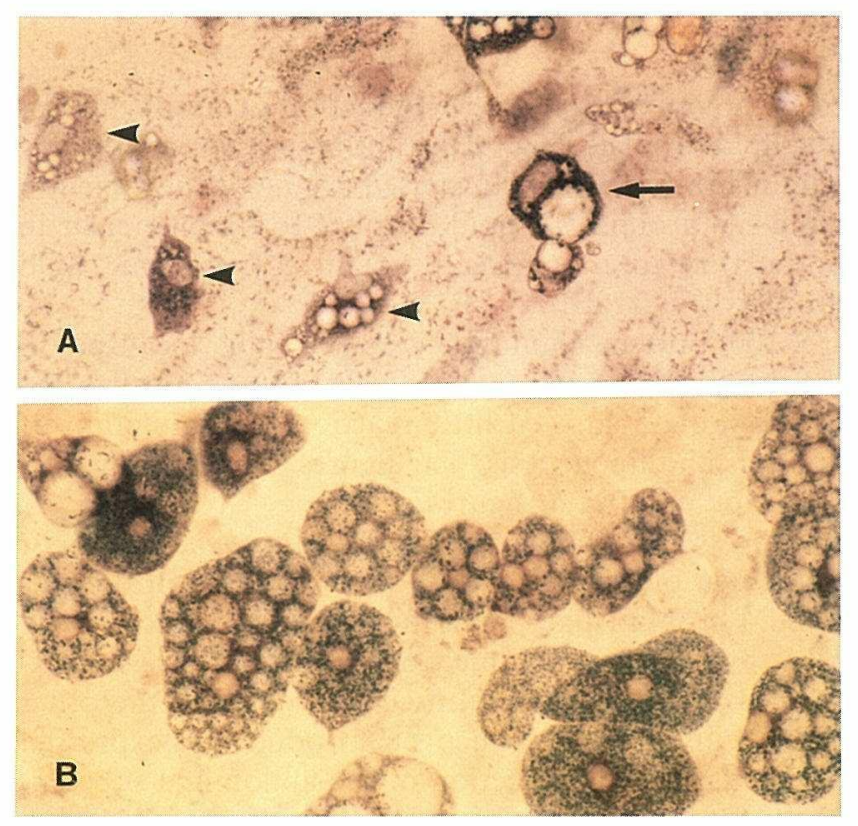

Fig. 7A \& B. Changes in $\alpha$-GPDH activity caused by stimulation of lipogenesis in cultured fat cells. A, control (no treatment). $\alpha$-GPDH activity in cytoplasm appears strong in round fat cells (arrow), but is weak in multilocular fat cells (arrowhead); B, administration for 7 days of $1 \mathrm{mU} / \mathrm{ml}$ insulin in culture. $\alpha$-GPDH activity in cytoplasm of the multilocular fat cells increased. ter of the cell and the cytoplasm was full of similarsized intracytoplasmic lipid droplets (Fig. 5A, B). In the unilocular fat cells, the intracytoplasmic lipid droplets became enlarged (Fig. 5C). These droplets were clearly observed with Oil red $\mathrm{O}$ staining.

$B)$ Enzyme histochemical findings. In the non-treatment group of fibroblast-like cells, multilocular fat cells and unilocular fat cells, I examined the histochemical enzyme activities of three enzymes which reflect the function of fat cells: G6PDH activity related to glucose metabolism and non-specific cellular function, HSL activity related to lipolysis and $\alpha-\mathrm{GPDH}$ activity related to lipogenesis. The fibroblast-like fat cells showed slight histochemical activity for each of the three enzymes. The unilocular fat cells showed comparatively strong histochemical activity of the three enzymes, and the multilocular fat cells exhibited moderate histochemical enzymatic activity (Fig. 6A, 7A, 8A).

Upon lipolytic stimulation by treatment with dibutyryl-cAMP, the fibroblast-like fat cells failed to show clear histochemical enzyme activity of any of the three enzymes. The multilocular and unilocular fat cells, on the other hand, showed increased histochemical enzyme activity of HSL (Fig. 6B). In particular, a marked increase of HSL activity was found in the unilocular fat
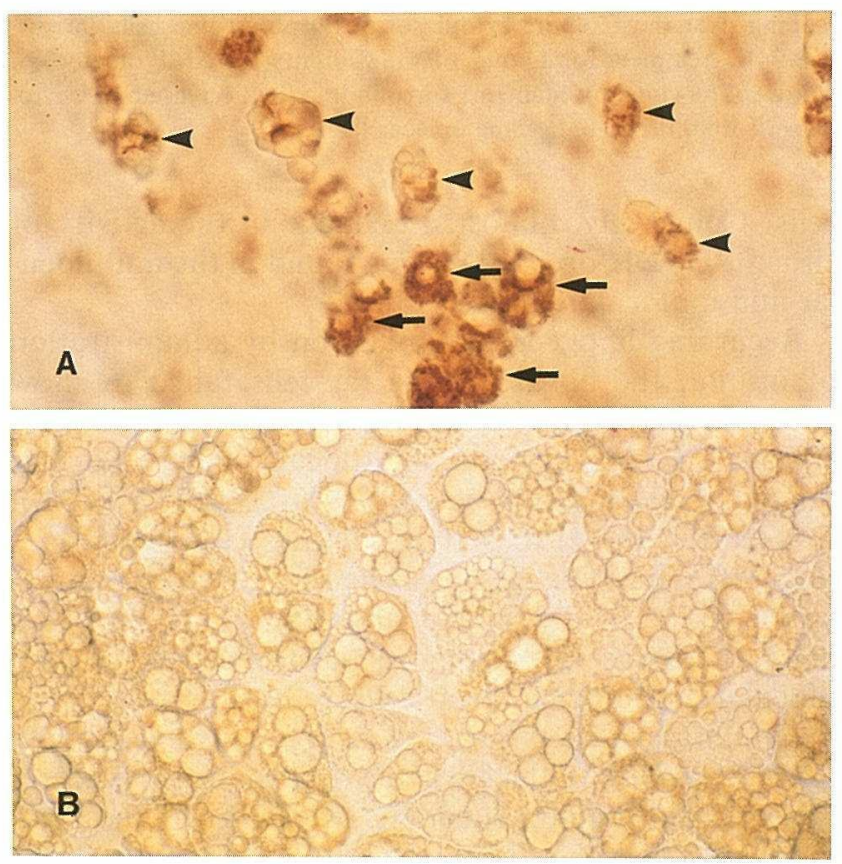

Fig. 8A \& B. Changes in HSL activity caused by stimulation of lipogenesis in cultured fat cells. A, control (no treatment). HSL activity in cytoplasm appears strong in round fat cells (arrow), but is weak in multilocular fat cells (arrowhead); B, administration for 7 days of 1 $\mathrm{mU} / \mathrm{ml}$ insulin in culture. HSL activity in cytoplasm of the cells descreased. 


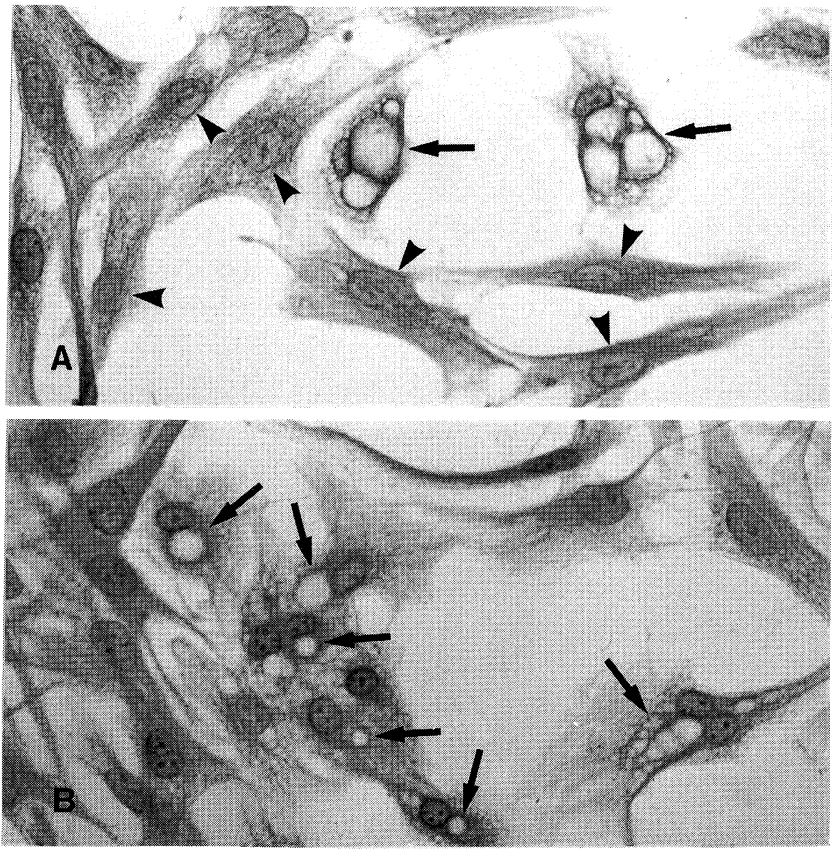

Fig. 9A \& B. Changes in immunocytochemical localization of vimentin filaments caused by stimulation of lipolysis in cultured fat cells. A, control (no treatment). The vimentin filament appears in a thin rim or crescent surrounding the intracytoplasmic lipid droplets in round fat cells (arrow). On the other hand, it appears in bundles extending over most of the cytoplasm in fibroblast-like cells (arrowhead); B, treatment for 4 hours of $1 \mathrm{mM}$ dibutyryl-cAMP on day 3 of culture. The vimentin filaments surrounding the decreased intracytoplasmic lipid droplete became unclear (arrow).

cells. Conversely, almost no change in the activity of either $\alpha$-GPDH or G6PDH was found in the multilocular and unilocular fat cells.

Regarding lipogenetic stimulation by administration of insulin, the fibroblast-like fat cells failed to show clear histochemical enzyme activity of any of the three enzymes. In contrast, the multilocular and unilocular fat cells had increased activity of $\alpha$-GPDH (Fig. 7B). Conversely, the HSL activity of these cells decreased (Fig. 8B). These changes in enzyme activity were particularly striking in the unilocular fat cells. On the other hand, there was little change in G6PDH activity in multilocular and unilocular fat cells.

Immuno-cytochemical localization of vimentin and $S-100$ protein. In the fibroblast-like fat cells, vimentin appeared in bundles extending over most of the cytoplasm. On the other hand, in multilocular and unilocular fat cells, the adipose conversion was more advanced and vimentin filaments appeared in a thin rim or crescent, surrounding the intracytoplasmic lipid droplets (Fig. 9A, 10A). Following lipolytic stimulation by treatment with dibutyryl-cAMP, the vimentin filaments surrounding the intracytoplasmic lipid droplets became un-
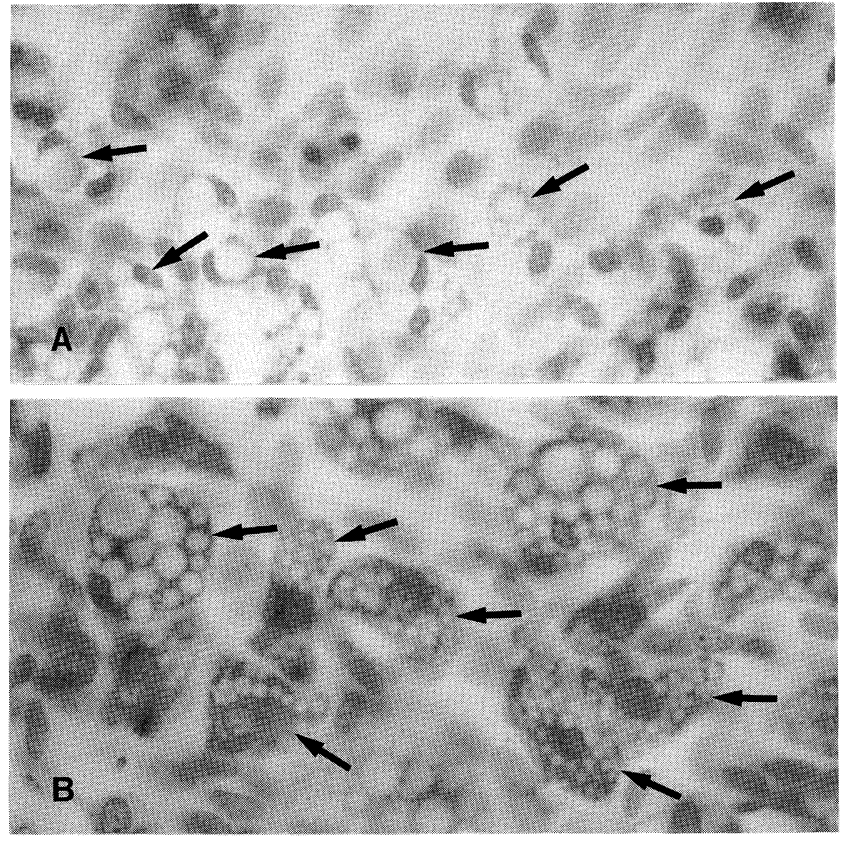

Fig. 10A \& B. Changes in immunocytochemical localization of vimentin filaments caused by the stimulation of lipogenesis in cultured fat cells. A, control (no treatment). The vimentin filament appears in a thin rim or crescent surrounding the intracytoplasmic lipid droplets in round fat cells (arrow); B, administration for 7 days of $1 \mathrm{mU} / \mathrm{ml}$ insulin in culture. Caging of the vimentin filaments around the increased intracytoplasmic lipid droplets became clear (arrow).

clear in conjunction with a reduction of intracytoplasmic lipid droplets (Fig. 9B). Lipogenetic stimulation by administration of insulin caused caging of the vimentin filaments around the lipid droplets to become clear in proportion to the increase of intracytoplasmic lipid droplets (Fig. 10B).

S-100 protein immuno-cytochemically localized in the cytoplasm of cultured fat cells, but the localization of the protein showed little reaction to stimulation of lipolysis and lipogenesis. The figures are not shown because the number of figures grows.

Expression of c-neu and pan-ras oncogene products. The c-neu oncogene product was expressed in the cultured fibroblast-like, multilocular and unilocular fat cells, but the pan-ras oncogene products were not expressed in any of the cultured fat cells. On the other hand, while the c-neu oncogene product was expressed in the histochemical section of the abdominal subcutaneous fat tissue of newborn rat, they were not found in that of mature rat. The pan-ras oncogene products were not expressed in either fat tissue. These figures are not shown. 


\section{DISCUSSION}

Investigators $(1,2,11,12,19,27,28,29)$ have divided mature fat cells into two fractions: the floating fraction composed of mature fat cells and the sedimental fraction composed of immature fat cells called preadipocytes, by digestion and centrifugation of mature fat tissue. Preadipocytes proliferate extensively under culture conditions and differentiate into mature fat cells.

It has been considered that the mature unilocular fat cells is in the terminal stage of differentiation and, thereby, lacks proliferative activity $(12,28)$. Recently, Sugihara et al. $(23,24,26)$ reported a new method called "ceiling culture" for culturing unilocular fat cells using their innate buoyancy in the culture medium. In this "ceiling culture" method, the dissociated unilocular fat cells dedifferentiated into fibroblast-like fat cells, i.e., immature fat cells, and then redifferentiated into unilocular fat cells, which represent the mature phase of fat cells after passing through the multilocular fat cell stage. They have further reported a simple culture method for fat cells derived from mature fat tissue fragments
(25). In this method, the fibroblast-like fat cells also proliferated extensively from fat tissue fragments, and redifferentiated into mature fat cells after passing through the multilocular fat cell stage. It is impossible to morphologically distinguish fibroblast-like fat cells derived from mature fat tissue fragments, from preadipocytes. The former, however, has a greater tendency to differentiate than the latter.

In this study, I used the above-mentioned culture technique to observe the changes in cellular morphology and function in the maturing phase of the fat cells. In general, it is known that immature fat cells differentiate more readily in co-culture with mature fat cells than in single-culture conditions $(3,21)$. The mature fat tissue fragment culture which I have adopted in the present method allows the above-mentioned co-culture to be carried out more simply. In addition to this advantage, the tissue fragment culture method appears to reflect cellular proliferation of fat tissue in vivo.

In the present study, I classified cultured fat cells into three phases in terms of morphology, and discuss their behavior. The first phase of the cells is the fibroblast-

\section{CONTROL LIPOLYSIS LIPOGENESIS (administration of insulin)}

\section{fibroblast-like fat cell}
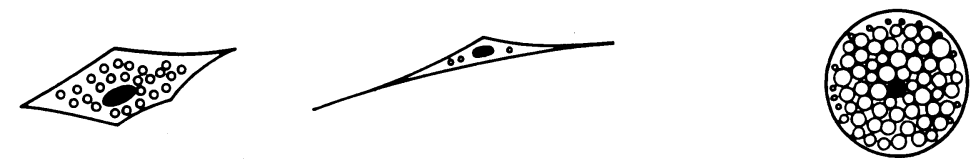
multilocular fat cell
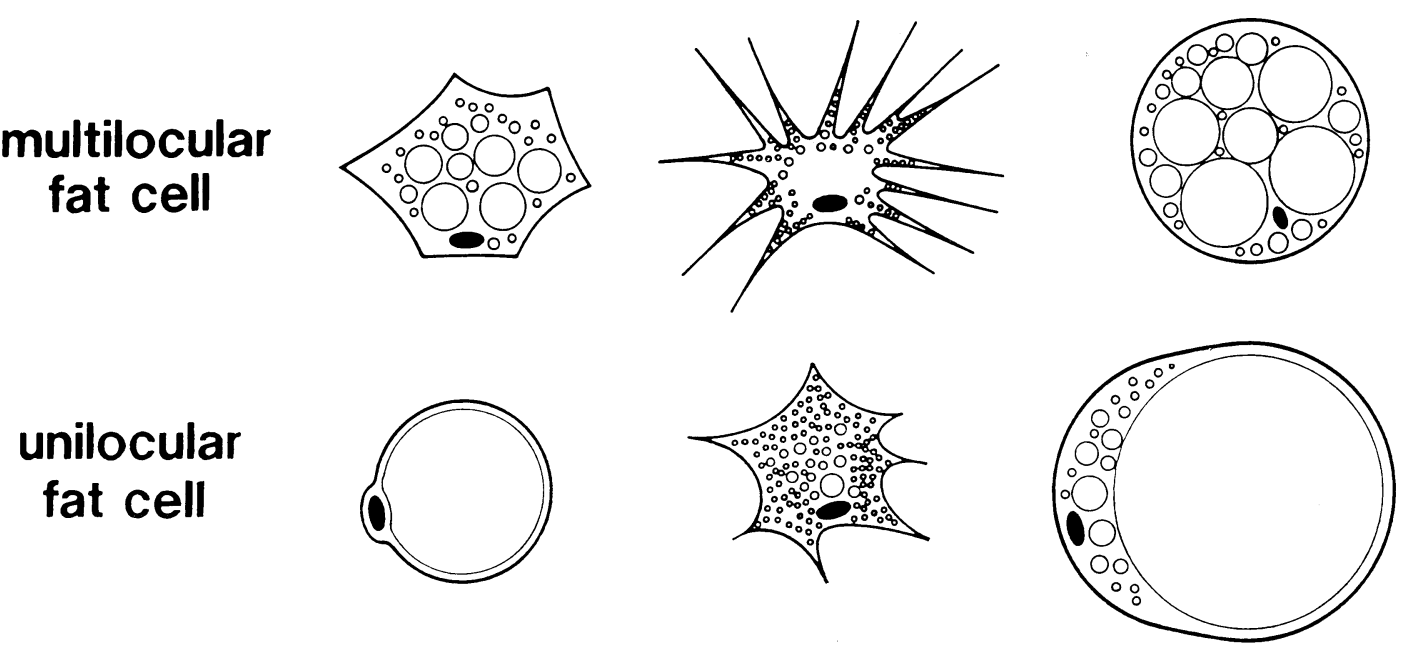

Fig. 11. Schematic drawing of morphological changes caused by stimulation of lipolysis and lipogenesis in the primary tissue fragment culture. The fibroblast-like fat cells, multilocular fat cells and unilocular fat cells retracted, and intracytoplasmic lipid droplets decreased following stimulation of lipolysis. On the other hand, these cells enlarged and became round, in conjunction with increases of intracytoplasmic lipid droplets by stimulation of lipogenesis. 
like fat cells, with a small number of fine intracytoplasmic lipid droplets, which appeared immediately to surround the tissue fragments and proliferated extensively. The second phase is the multilocular fat cells, which have numerous large intracytoplasmic lipid droplets, resulting from lipogenesis of the above-mentioned cells. The third phase of the cells is the unilocular fat cells, with a single large intracytoplasmic droplet, which grew by means of further lipogenesis.

Histochemically, the fibroblast-like fat cells showed low enzyme activity of both HSL participating in lipolysis and $\alpha$-GPDH participating in lipogenesis. On the other hand, the histochemical enzyme activities of the unilocular fat cells were high in both cases. The multilocular fat cells showed moderate enzyme activity. The enzyme activities of multilocular and unilocular fat cells were clearly elevated by administration of dibutyrylcAMP, which is a second messenger of the lipolytic factors (e.g., epinephrine, ACTH, etc.), and treatment with insulin. The above demonstrates that cultured fat cells derived from tissue fragments actively metabolize triglycerides and respond to hormones. The potential proliferative abilities of the cultured fat cells, which were confirmed by uptake of bromo-deoxyuridine, were higher in fibroblast like fat cells than in unilocular fat cells, and moderate in multilocular fat cells. This indicates that the proliferative ability of cultured fat cells is dependent on cellular morphology. It was determined that the fibroblast-like fat cell is the proliferating type, the unilocular fat cell is the mature type and the multilocular fat cell is the transitional cell type. In addition, I observed the functional changes in conjunction with morphological ones: the cells retracted along with small lipid droplet formation in lipolysis, and became rounded with increases in size of these droplets during lipogenesis (Fig. 11). The ability to simultaneously observe morphology and function of fat cells is an advantage of the enzyme-cytochemical method.

It is thought that the strong HSL activity, exhibited in fat cells with increased intracytoplasmic lipid droplets in lipolysis is dependent on the size of the lipid droplets which reflects the fundamental nature of the enzyme, that is, the amount of triglycerides. Further, judging from the radial arrangement of decreased lipid droplets, it can be presumed that the lipid droplets migrate to the peripheral cytoplasm along radially arranged microtubles (22). It is, therefore, thought that the migrated lipid droplets in the surface area, which expanded by retraction of the cell, are easily metabolized in order to be released from the cell to the extracellular space in the cell membrane. On the other hand, it is thought that the increase and enlargement of the intracytoplasmic lipid droplets by insulin are due to two chemical actions; one is the activation of lipogenesis which is reflected by the increase of $\alpha$-GPDH activity and the other is the anti-lipolytic action that reflected the inhibition of HSL activity (28).

It was presumed that vimentin, which is an inter-

\section{PROLIFERATION} PHASE
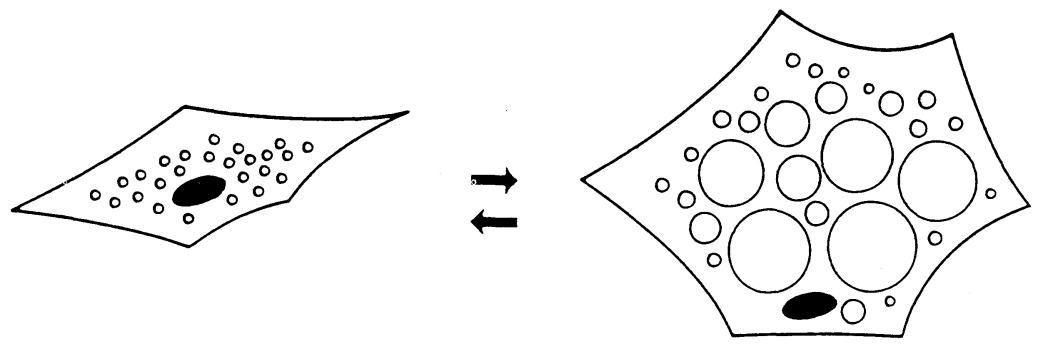
fibroblast-like fat cell

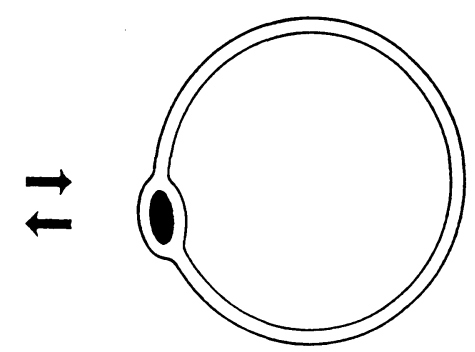

\section{DIFFERENTIATION} PHASE

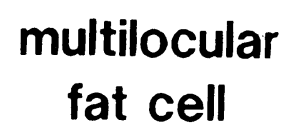

\section{unilocular fat cell}

Fig. 12. Schematic drawing of the proliferation and differentiation of fat cells in the primary tissue fragment culture. The fibroblast-like fat cells proliferated extensively from fat tissue fragments containing unilocular fat cells, and redifferentiated into unilocular fat cells through multilocular fat cells. 
mediate filament protein of cytoskeleton, was localized around the intracytoplasmic lipid droplets, and its localization changed following treatment with dibutyrylcAMP and insulin. The localization of vimentin in fat cells is closely correlated with the cellular function, e.g., lipolysis and lipogenesis. The vimentin-positive rim resulting from lipogenesis clearly supports the report (5) that vimentin creates a form of compartmentalization of lipid droplets.

The oncogene product of c-neu, which is homologous with the receptor protein to epidermal growth factor (EGF), was expressed in subcutaneous fat tissue in vivo of the newborn rat, but not in that of the mature rat. In culture, c-neu oncogene product was strongly expressed in fibroblast-like fat cells, i.e., highly proliferative fat cells.

In conclusion, fat cells in primary culture of this study clearly demonstrate a proliferative ability, and possess the proper morphology and functions associated with the respective developmental phase (Fig. 12). The simple method of culturing fat tissue fragments makes it possible to obtain a variety of fat cells in vitro, and can be applied to cell biological studies of fat cells.

Acknowledgements. I wish to thank Professor H. Sugihara for his critical and informative review of this manuscript. I also thank Drs. M. Yonemitsu and S. Toda for their valuable suggestions and Ms. Lisa Tsukamoto for reviewing the English. The excellent technical assistances of H. Ideguchi, S. Nakahara and F. Mutoh are gratefully acknowledged.

\section{REFERENCES}

1. Björntorp, P., Karlsson, M., Pertoft, H., Pettersson, P., SJöström, L., and SмITH, U. 1978. Isolation and characterization of cells from rat adipose tissue developing into adipocytes. J. Lipid Res., 19: 316-324.

2. Björntorp, P., Karlsson, M., Pettersson, P., and SYNIEWSKA, G. 1980. Differentiation and function of rat adipocyte precursor cells in primary culture. J. Lipid Res., 21: 714-723.

3. Carraro, R., Lu, Z., Li, Z., Johnson, J.E. Jr., and Gregerman, R. 1990. Adipose tissue islets: tissue culture of a potential source of fat cells in the adult rat. FASEB J., 4: 201207.

4. Eggstein, M. and Kuhlman, E. 1974. Triglyceride and glycerol. In Methods of Enzymatic Analysis, vol. 4 (H.U. Bergmeyer, ed.). Verlag Chemie, Weinheim/Academic Press, New York, London, pp. 1825-1831.

5. Franke, W.W., Hergt, M., and Grund, C. 1987. Rearrangement of the vimentin cytoskeleton during adipose conversion: formation of an intermediate filament cage around lipid globules. Cell, 49: 131-141.

6. Furth, M.E., Aldrich, T.H., and Cordon-Cardo, C. 1987. Expression of ras proto-oncogene proteins in normal human tissues. Oncogene, 1: 47-58.

7. Gratzner, H.G., Leif, R.C., Ingram, D.J., and Castro, A. 1975. The use of antibody specific for bromodeoxyuridine for the immunofluorescent determination of DNA replication in sin- gle cells and chromosomes. Exp. Cell Res., 95: 88-94.

8. Gratzner, H.G. 1982. Monoclonal antibody to 5-bromo- and 5-iododeoxyuridine: a new reagent for detection of DNA replication. Science, 218: 474-475.

9. Green, H. and Kehinde, O. 1975. An established preadipose cell line and its differentiation in culture. II. Factors affecting the adipose conversion. Cell, 5: 19-27.

10. Налmoto, H., Kato, K., Suzuki, F., and Nagura, H. 1985. The ultrastructural changes of S-100 protein localization during lipolysis in adipocytes: an immunoelectron-microscopic study. Am. J. Pathol., 121: 185-191.

11. Hausmann, G.J., Campion, D.R., and Martin, R.J. 1980. Search for the adipose precursor cell and factors that promote its differentiation. J. Lipid Res., 21: 657-670.

12. Hiragun, A. 1985. Cell and tissue culture models of adipocyte development. In New Perspectives in Adipose Tissue: Structure, Function and Development (A. Cryer and R.L.R. Van, eds.). Butterworth, London, pp. 333-352.

13. KoKaI, Y., Cohen, J.A., Drebin, J.A., and Greene, M.I. 1987. Stage- and tissue-specific expression of the neu oncogene in rat development. Proc. Natl. Acad. Sci. USA, 84: 84988501 .

14. Kumei, Y., Takasugi, Y., and Namiki, M. 1988. A basic study of the rat and human fat cell in primary culture. Proceed. 8th Cong. ZASSO, 64-65. (in Japanese)

15. Négrel, R., Grimaldi, P., and Alihaud, G. 1978. Establishment of preadipocyte clonal line from epididymal fat pad of ob/ob mouse that responds to insulin and to lipolytic hormones. Proc. Natl. Acad. Sci. USA, 75: 6054-6058.

16. Pearse, A.G.E. 1972. NAD-liked Glycerophosphate dehydrogenase. In Histochemistry: Theoretical and Applied, vol. 2, Analytical Technology, 3rd ed., Churchill Livingstone, London, pp. 929-930.

17. Pearse, A.G.E. 1972. Glucose-6-phosphate dehydrogenase. In Histochemistry: Theoretical and Applied, vol. 2, Analytical Technology, 3rd ed., Churchill Livingstone, London, pp. 937938.

18. Pearse, A.G.E. 1972. The tween method for lipase after Gomori. In Histochemistry: Theoretical and Applied, vol. 2, Analytical Technology, 3rd ed., Churchill Livingstone, London, pp. 1309.

19. PoznAnski, W.J., Waheed, I., and Van, R. 1973. Human fat cell precursors: morphologic and metabolic differentiation in culture. Lab. Invest., 29: 570-576.

20. RodBell, M. 1964. Metabolism of isolated fat cells: I. Effects of hormones on glucose metabolism and lipolysis. J. Biol. Chem., 239: 375-380.

21. Shillabeer, G., Forden, J.M., and LaU, D.C.W. 1989. Induction of preadipocyte differentiation by mature fat cells in the rat. J. Clin. Invest., 84: 381-387.

22. Sugihara, H., Yonemitsu, N., Ohta, K., Miyabara, S., and Nagayama, A. 1983. Immunocytochemistry of the microtubles of fat-laden cells: brown fat cells and adrenocortical cells in primary monolayer culture. Histochemistry, 79: 227-236.

23. Sugihara, H., Yonemitsu, N., Miyabara, S., and Yun, K. 1986. Primary cultures of unilocular fat cells: characteristics of growth in vitro and changes in differentiation properties. Differentiation, 31: 42-49.

24. Sugihara, H., Yonemitsu, N., Miyabara, S., and Toda, S. 1987. Proliferation of unilocular fat cells in the primary culture. J. Lipid Res., 28: 1038-1045.

25. Sugihara, H., Funatsumaru, S., Yonemitsu, N., Miyabara, S., Toda, S., and HikichI, Y. 1989 . A simple culture method 
of fat cells from mature fat tissue fragments. J. Lipid Res., 30: 1987-1995.

26. Sugihara, H., Funatsumaru, S., and Hikichi, Y. 1991. Proliferation of mature unilocular fat cells differentiated from rat preadipocytes. In Progress in obesity research 1990 (Y. Oomura, et al. eds.). John Libbey \& Co. Ltd., London, pp. 197-200.

27. Van, R.L.R., BaYliss, C.E., and Roncari, D.A.K. 1976. Cytological and enzymological characterization of adult human adipocyte precursors in culture. J. Clin. Invest., 58: 699-704.
28. VAN, R.L.R. 1985. The adipose precursor cells. In New Perspectives in Adipose Tissue: Structure, Function and Development (A. Cryer, and R.L.R. Van, eds.). Butterworth, London, pp. 353-382.

29. Wiederer, O. and LOFFLeR, G. 1987. Hormonal regulation of the differentiation of rat adipocyte precursor cells in primary culture. J. Lipid Res., 28: 649-658.

(Received for publication, July 21, 1994

and in revised form, September 30, 1994) 